\title{
PENINGKATAN PENJUALAN PRODUK KERAJINAN ROTAN MELALUI DIVERSIFIKASI PRODUK PADA MASYARAKAT KECAMATAN MEDAN SUNGGAL
}

\author{
Charles Fransiscus Ambarita ${ }^{*}$, Muhammad Andi Abdillah Triono ${ }^{1}$, Heri Soeprayogi ${ }^{1}$, \\ Dody Feliks Pandimun Ambarita ${ }^{1}$
}

\author{
Jurusan Pendidikan Ekonomi, Fakultas Ekonomi, Universitas Negeri Medan, Medan, Indonesia \\ *Penulis Korespodensi: charles.ambarita@yahoo.com
}

\begin{abstract}
Abstrak
Tujuan pengabdian ini untuk membantu mitra dalam meningkatkan produktivitas dan penjualan usahanya sehingga dapat meningkatkan penjualan produk kerajinan rotan bermuatan budaya daerah. Luaran yang dihasilkan dari pengabdian ini antara lain: (1) produk kerajinan rotan bermuatan budaya daerah: dan (2) laporan keuangan UKM. Metode yang dipakai untuk mencapai tujuan pengabdian ini adalah pendidikan dan praktek diversifikasi kerajinan rotan bermuatan budaya daeerah. Kegiatan pengabdian ini dilaksanakan di kecamatan Medan Sunggal Jalan Amal Nomor 121 C Kotamadya Medan Provinsi Sumatera Utara. Hasil capaian kegiatan yang telah dihasilkan adalah: (1) mitra telah memperoleh pendidikan dan keterampilan dalam melakukan diversifikasi produk kerajinan rotan bermuatan budaya daerah, dan (2) mitra memperoleh teknologi tepat guna berupa mesin pemotang rotan untuk meningkatkan penjualan produknya.
\end{abstract}

Kata kunci: Diversifikasi; Rotan; Penjualan; Pendidikan.

\begin{abstract}
The purpose of this dedication to increasing productivity and sales of their businesses so as to increase sales rattan handicraft products with regional culture. Resultant of output from this dedication activity, such as: (1) ) Rattan Product with local feature; and (2) Financial statement for Small-Medium Enterprises. The method used to achieve the purpose of dedication activity are education and practicing diversification of rattan product with local feature. This activity located in Medan Sunggal District, Amal Street Number 121C, Medan City, North Sumatra. The activities of achievement result are: (1) Partners getting knowledge and skill diversification of rattan product with local feature; and (2) Partners got an efficient technology like cutter device for rattan to increase their sales.
\end{abstract}

Keywords: Diversification; Rattan, Sales; Education.

\section{PENDAHULUAN}

Rotan adalah sekelompok palma dari puak (tribus) Calameae yang memiliki habitus memanjat, terutama Calamus, Daemonorops, dan Oncocalamus. Puak Calameae terdiri dari sekitar enam ratus anggota, dengan daerah persebaran di bagian tropis Afrika, Asia dan Australasia.

Rotan merupakan tanaman sejenis palm yang merambat dan dapat tumbuh panjang mencapai 100 meter lebih (Soedjono , 2008). Batang rotan biasanya langsing dengan diameter $2-5 \mathrm{~cm}$, beruas-ruas panjang, tidak berongga, dan banyak yang dilindungi oleh duriduri panjang, keras, dan tajam. Rotan yang diameternya besar biasanya digunakan untuk konstruksi mebel, sedangkan yang diameter kecil digunakan untuk pengikat dan anyaman (Januminro, 2000).

Secara umum, rotan memiliki karakteristik kaku tetapi elastis dan kuat. Rotan merupakan substrat yang pejal, kuat, dan ulet sehingga dapat dibentuk lengkung, dipilin, dan dianyam (Iensufie, 2008). Rotan cepat tumbuh dan relatif mudah dipanen serta ditransportasi. Ini dianggap membantu menjaga kelestarian hutan, karena orang lebih suka memanen rotan daripada kayu. Sebagai bahan alami, rotan sudah sejak lama dikenal oleh masyarakat Indonesia dan dapat digunakan dalam berbagai kebutuhan hidup sehari-hari.

Tanaman rotan terkenal memiliki nilai tinggi untuk industri kreatif kerajinan karena berbagai manfaat yang diperoleh baik dalam hal bahan baku mebel, misalnya kursi, meja tamu, serta rak buku maupun berbagai kerajinan industri kreatif. Hal itu dikarenakan rotan memiliki banyak kelebihan seperti ringan, kuat, elastis/mudah dibentuk sehingga tidak mudah patah saat dibentuk. Kondisi itu menjadikan terdapat beberapa masyarakat di Kota Medan, khususnya Kecamatan Medan Sunggal berwirausaha mengelola 
rotan menjadi barang kerajinan seperti barang mebel maupun berbagai barang lainnya.

Di kota Medan, khususnya Jalan Amal No. 121 C Sunggal Medan, terdapat industri kerajinan rotan yang memproduksi berbagai jenis kerajinan rotan, seperti keranjang parsel, kursi rotan, tudung saji dan produk lainnya yang bernama UD. Syah Putra Ratan yang dikelola oleh Ibu Siti Zahara. Usaha Dagang ini sudah berlangsung lebih kurang 18 tahun dan memiliki 5 orang karyawan.

Kunjungan yang dilakukan oleh tim pengabdi tanggal 21 April 2019, masyarakat Kecamatan Medan Sunggal yang berwirausaha kerajinan rotan biasanya hanya membuat produk dengan cara manual yaitu dengan memanfaatkan alat-alat seadanya dan hasil kerajinan yang diciptakan juga masih sangat sederhana.

Diversifikasi produk kerajinan rotan tentu saja dapat dilakukan oleh masyarakat Kecamatan Medan Sunggal untuk meningkatkan penjualan produknya yang pada akhirnya akan meningkatkan pendapatan usaha. Diversifikasi produk kerajinan rotan dapat dilakukan dengan berbagai bentuk, ukiran, serta dihias dengan sentuhan perpaduan warna yang unik sehingga menambah keindahan produk seperti corak khas suku Batak yang merupakan ciri khas dari Sumatera Utara.

Diversifikasi produk ini memerlukan kreativitas dan inovasi dari pengrajin rotan di Kecamatan Medan Sunggal. Oleh karena itu pengrajin memerlukan pendidikan, pelatihan, dan praktek diversifikasi produk kerajainan rotan agar produk yang dihasilkan dapat menambah nilai jualnya sehingga penjualan dari usaha dapat meningkat.

\section{BAHAN DAN METODE}

Bahan yang digunakan dalam kegiatan praktek diversifikasi produk kerajinan rotan bermuatan budaya daerah adalah cat acrylic, kuas, contoh gambar dan produk kerajinan rotan. Metode pelaksanaan kegiatan program pengabdian kepada masyarakat ini dilakukan dengan pendidikan, pelatihan dan praktek diversifikasi produk kerajinan rotan bermauatan budaya daerah.

Tahapan-tahapan yang akan dilaksanakan dalam menyelesaikan masalah mitra adalah: (1) menjustifikasi masalah prioritas yang dihadapi mitra; (2) menggunakan metode pendekatan yang tepat untuk menyelesaikan persoalan mitra; (3) menyusun rencana kerja yang didukung oleh partisipasi mitra; dan (4) pendidikan, pelatihan, dan praktek diversifikasi produk kerajinan rotan bermuatan budaya daerah.

Langkah-langkah kerja dalam melaksanakan kegiatan pengabdian pada masyarakat ini adalah sebagai berikut: (1) Kegiatan penyuluhan. Kegiatan ini bertujuan untuk menyamakan persepsi kepada pengrajin rotan di Kecamatan Medan Sunggal tentang kegiatan yang akan dilakukan oleh tim pengabdi; dan (2) Pelatihan dan praktek diversifikasi produk kerajinan rotan bermuatan budaya daerah. Kegiatan ini dimaksudkan agar mitra dan masyarkat pengrajin rotan di Kecamatan Medan Sunggal memperoleh pengetahuan dan keterampilan dalam melakukan diversifikasi produk kerjajinan rotan bermuatan budaya daerah.

\section{HASIL DAN PEMBAHASAN}

Produksi yang selama ini dapat dihasilkan UD Syah Putra Ratan yang dikelola oleh Ibu Siti Zahara mampu memproduksi kerajinan buah dari rotan berupa keranjang parsel rata-rata 120-150 unit per bulan dengan harga jual Rp.10.000-Rp.40.000 per buah tergantung ukuran. Di samping keranjang buah, kursi rotan juga merupakan hasil kerajinan yang biasanya diproduksi. Kursi rotan diproduksi rata-rata 70-90 unit setiap bulan dengan harga Rp. 100.000- Rp.500.000 per buah tergantung model dan ukuran. Kemudian tudung saji mampu diproduksi rata-rata 100-120 unit per bulan dengan harga jual Rp.5.000-15.000 per buah tergantung ukuran.

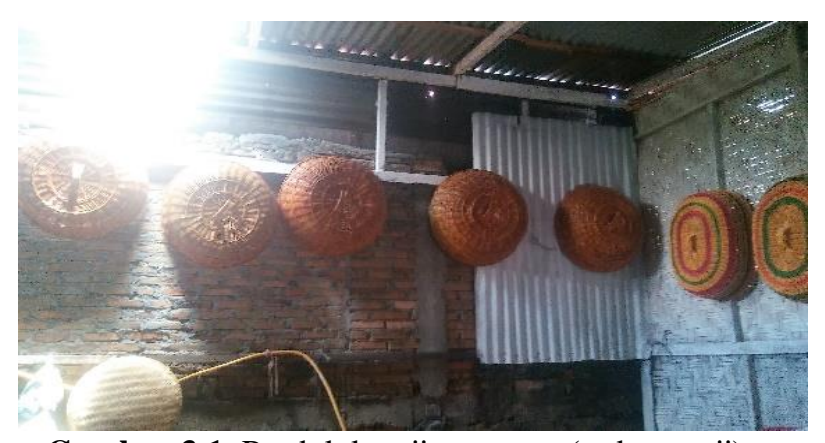

Gambar 3.1. Produk kerajinan rotan (tudung saji).

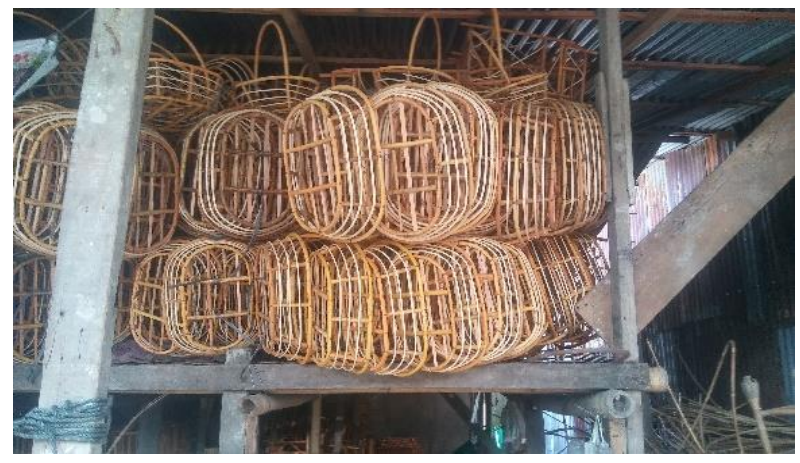

Gambar 3.2. Produk kerajinan rotan (keranjang buah).

Produksi hasil kerajinan rotan tersebut menggunakan alat seadanya dan tanpa ada diversifikasi produk yang dilakukan oleh pengrajin rotan di Kecamatan Medan Sungga khususnya UD Syah Putra Ratan. Potensi yang dimiliki dapat lebih ditingkatkan dengan strategi diversifikasi produk seperti penambahan jenis produk kap lampu dan vas bunga dari rotan dengan aneka bentuk, desain, ukiran, warna, corak yang unik dan berciri khas budaya daerah. Di samping penambahan produk, diversifikasi juga dapat dilakukan dengan menambah nilai seni pada produk yang sudah dihasilkan selama ini seperti keranjang buah. 
Keranjang buah tersebut dilukis dengan sentuhan seni bermotif budaya daerah sehingga nilai jual dari keranjang tersebut bertambah dan memungkinkan penjulan dapat meningkat.

Pengabdian yang dilakukan oleh tim pengabdi dari Universitas Negeri Medan di lokasi mitra UD Syah Putra Ratan yang dikelola Ibu Siti Zahara Jalan Amal nomor $121 \mathrm{C}$ Kecamatan Medan Sunggal dihadiri oleh pengrajin rotan dan masyarakat setempat di daerah Kecamatan Medan Sunggal. Adapun kegiatan yang dilakukan oleh tim pengabdi adalah sebagai berikut:

\section{1) Kegiatan penyamaan persepsi}

Kegiatan penyamaan persepsi ini bertujuan untuk menyamakan persepsi dengan mitra dan pengrajin serta masyarakat Kecamatan Medan Sunggal tentang program yang akan dilakukan tim pengabdi. Program yang akan dilakukan berupa pelatihan, pendidikan, keterampilan dan praktek diversifikasi produk kerajinan rotan bermuatan budaya daerah.

Pengabdian ini dilaksanakan tanggal 5 Oktober 2019 di Kecamatan Medan Sunggal di lokasi mitra UD Syah Putra Ratan yang dikelola oleh Ibu Siti Zahara. Kegiatan pengabdian ini dihadiri oleh 25 orang yang terdiri dari pengrajin rotan dan masyarakat setempat.

Pelakasana kegiatan ini adalah dosen Universitas Negeri Medan yang terdiri dari Charles Fransiscus Ambarita (dosen Pendidikan Ekonomi), Muhammad Andi Abdillah Triono (Dosen Manajemen), Drs. Heri Soeprayogi (Dosen Seni Rupa), dan Dody Feliks Pandimun Ambarita (Dosen PGSD). Dalam membantu kegiatan pengabdian ini tim pengabdi dibantu oleh 2 orang mahasiswa dari program studi pendidikan ekonomi yaitu Putra One Harefa dan Muhammad Fathir Rizky. Dalam kegiatan ini juga hadir perwakilan dari LPPM Unimed yaitu Bapak Saut.

Hasil yang didapatkan dari kegiatan penyamaan persepsi ini adalah mitra dan pengrajin rotan serta masyarakat Kecamatan Medan Sunggal memperoleh informasi tentang kegiatan lanjutan yang akan dilakukan oleh tim pengabdi yaitu pelatihan dan praktek diversifikasi produk kerajinan rotan bermuatan budaya daerah.

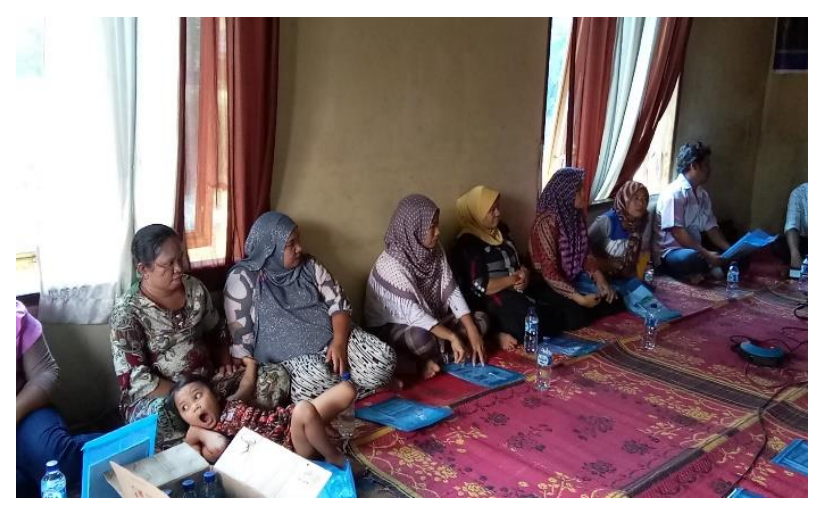

2) Kegiatan praktek diversifikasi produk kerajinan rotan bermuatan budaya daerah

Praktek diversifikasi produk kerajinan rotan bermuatan budaya daerah ini dilaksanakan pada tanggal 19 Oktober 2019 di rumah Ibu Siti Zahara yang merupakan mitra pengabdian. Adapun alamat mitra berlokasi di jalan Amal Nomor 121 C Kecamatan Medan Sunggal. Kegiatan pengabdian ini dihadiri oleh 22 orang peserta yang terdiri dari mitra pengabdian, pengrajin rotan dan masyarakat setempat yang berdomisili di Kecamatan Medan Sunggal. Kegiatan ini berlangsung dari jam 09.00-13.00 WIB.

Sama halnya dengan kegiatan penyamaan persepsi yang sebelumnya dilakukan oleh tim pengabdi, kegiatan pengabdian yang bertema praktek diversifikasi produk kerajinan rotan bermuatan budaya daerah ini dilaksanakan oleh 4 orang dosen dari prodi pendidikan ekonomi, prodi manajemen, prodi seni rupa dan PGSD serta dibantu oleh 2 orang mahasiswa dari program studi pendidikan ekonomi. Dalam kegiatan ini, Dosen dari program studi seni rupa lebih banyak mengambil peran yaitu Drs. Heri Soeprayogi. Beliau mengawali dengan memberikan ceramah dan berbagi informasi kepada mitra dan peserta pelatihan tentang konsep diversifikasi produk kerajinan rotan bermuatan budaya daerah. Setelah teori-teori yang disampaikan acara dilanjutkan dengan praktek diversifikasi produk kerajinan rotan bermuatan budaya daerah. Mitra dan peserta mendapatkan pengetahuan dan keterampilan tentang diversifikasi produk kerajinan rotan bermuatan budaya daerah melalui sesi tanya jawab. Produk yang dilakukan diversifikasi adalah keranjang buah. Awal nya keranjang buah yang dihasilkan sangat polos tanpa ada variasi dan sentuhan seni, setelah kegiatan praktek diversifikasi ini keranjang buah tersebut menjadi lebih menarik dengan ukiran dari budaya daerah Sumatera Utara.

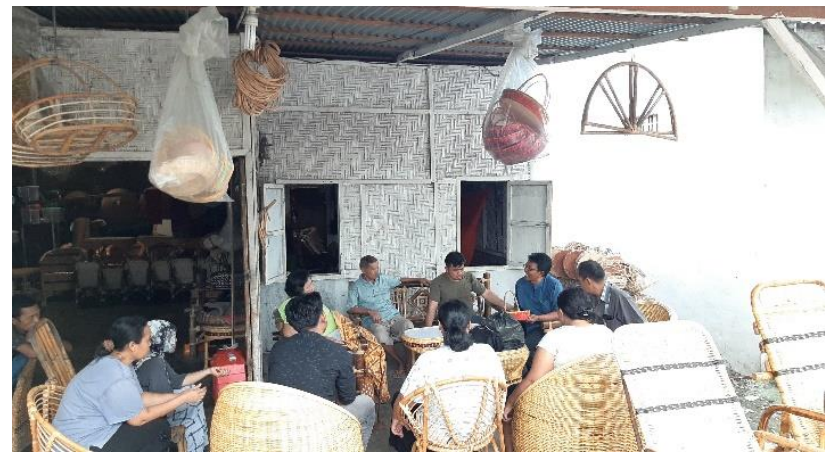

Gambar 3.4 Praktek Diversifikasi Produk Kerajinan Rotan.

Gambar 3.3. Kegiatan penyamaan persepsi. 


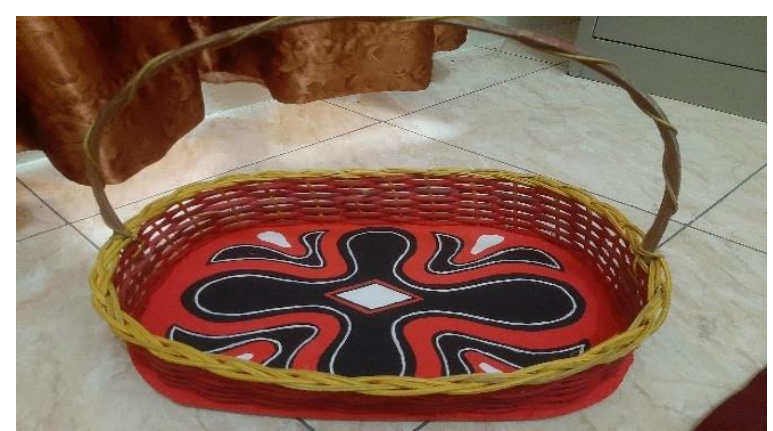

Gambar 3.5. Produk Kerajinan Rotan Bermuatan Budaya Daerah.

\section{KESIMPULAN}

Adapun kesimpulan dari kegiatan pelaksanaan pengabdian pada masyarakat ini adalah sebagai berikut: (1) mitra, pengrajin, dan masyarakat Kecamatan Medan Sunggal memperoleh pengetahuan, pendidikan, pelatihan dan praktek diversifikasi produk kerajinan rotan bermuatan budaya daerah; (2) mitra memperoleh tekonologi tepat guna untuk meningkatkan produksi sehingga pada akhirnya dapat meningkatkan penjualan; dan (3) peningkatan penjualan bagi usaha dagang Syah Putra Ratan melalui diversifikasi produk.

Program lanjutan yang akan dilakukan oleh tim pengabdi adalah melakukan monitoring dan evaluasi kegiatan sehingga kegiatan ini dapat dilakukan secara berkelanjutan dan tujuan dari pengabdian ini yaitu peningkatan penjualan produk kerajinan rotan bermuatan budaya daerah dapat tercapai.

\section{UCAPAN TERIMA KASIH}

Ucapan terima kasih yang setulus tulusnya tim pengabdi sampaikan kepada Universitas Negeri Medan dan Lembaga Penelitian dan Pengabdian Kepada Masyarakat Unimed atas dana dan bimbingannya dari awal hingga saati ini kegiatan pengabdian dilaksanakan. Semoga kegiatan pengabdian ini berdaya guna bagi masyarakat sehingga salah satu peran perguruan tinggi yaitu melaksanakan pengabdian pada masyakarat dapat tercapai secara maksimal.

\section{DAFTAR PUSTAKA}

Eskak, Edi. 2014. Kajian Pengembangan Mebel Rotan di Sumbawa Barat. Jurnal Dinamika Kerajinan dan Batik. Volume 31 Nomor 1 Tahun 2014. Diakses Tanggal 22 April 18.

Iensufi, T. 2008. Furniture \& Handicraft Berkualitas Ekspor. Jakarta: Erlangga.

Januminro, C.F.M. 2000. Rotan Indonesia. Yogyakarta: Kanisius.

Karo-karo, Terip. 2014. Mesin Pengolah Rotan. Diakses pada 22 April 2018. http://pondokbangkaro.com/article/17660/-mesin-pengolah-rotan--.html
Soedjono, dkk. 2008. Kerajinan Rotan. Bandung: Angkasa.

Syofyan, Muhammad Furqan. 2017. Tinjauan Kerajinan Kursi Rotan Dari Segi Teknik Pembuatan di UD. Syah Putra Ratan Medan. Skripsi. 2017. Fakultas Bahasa dan Seni. Universitas Negeri Medan. 